OPEN ACCESS

Edited by:

Chunxia Qi,

Beijing Normal University, China

Reviewed by: Adrian Sin Loy Loh,

National Junior College, Singapore Helle Marie Skovbjerg,

Design School Kolding, Denmark

*Correspondence:

Marianne Lykke mlykke@hum.aau.dk

Specialty section:

This article was submitted to

STEM Education,

a section of the journal

Frontiers in Education

Received: 02 March 2021

Accepted: 31 July 2021

Published: 20 September 2021

Citation:

Lykke M, Skov M and Jantzen C (2021)

High Pulse: Exploring the Exhibit

Features of a Collaborative, Whole-

Body Exhibition for Experiential

Learning in Science Centers.

Front. Educ. 6:675007.

doi: 10.3389/feduc.2021.675007

\section{High Pulse: Exploring the Exhibit Features of a Collaborative, Whole-Body Exhibition for Experiential Learning in Science Centers}

\author{
Marianne Lykke*, Mette Skov and Christian Jantzen \\ Department of Communication and Psychology, Aalborg University, Aalborg, Denmark
}

This research work explored how collaborative, whole-body exhibits affect science learning in informal out-of-school settings. Specifically, the study investigated how exhibit features guided visitors to engage actively in experiential exploration of the exhibition topics, and how these exhibit features guided visitors to make sense of the interaction and transform experiences into knowledge. The study took place at a science center in Denmark. The context was the PULSE exhibition consisting of eight individual exhibits that aimed at facilitating discussions on the importance of bodily activities for physical and social well-being. Together the exhibits formed the traditional parts of a family home and core family activities, for example, a kitchen for cooking. Each exhibit was built on experiencing through physical activity and revolved around one or several biological phenomena, for example, balance, coordination, and suppleness. All exhibits were designed for group interactions. The study explored the visitors' experiences with the exhibition using data from walking interviews with 34 visitor groups comprising a total of 108 visitors. Each exhibit was composed of a set of exhibit features, and the study analyzed how these features supported the experiential learning. The findings showed that the whole-body activities and group collaborations formed the greatest motivation to participate in the exhibition and, thereby, explore the themes of the exhibition. As regard the visitors' learning, most groups expressed the joy of physical movement, group work, and need of strategy planning to carry out the activities in their conversations, whereas only a few groups seemed to perceive and reflect on the biological phenomena presented. Due to the physically demanding activities and the required social collaboration, the visitors were not able to engage in in-depth explorations of the exhibition's scientific themes. In some exhibits where scientific information was incorporated naturally in the activity through interactive videos, the visitors talked about the themes as a natural part of the activity. Altogether, the findings have been used to outline a set of design principles for collaborative whole-body exhibits.

Keywords: exhibit features, collaborative, whole-body exhibition, experiential learning, science centers, mediational means and mediated action 


\section{INTRODUCTION}

Science centers are often described as the third generation of science museums, characterized by informal learning and interactive exhibits aimed at engaging visitors in understanding scientific laws, principles, and phenomena rather than presenting collections of scientific objects (Pedretti 2002; Friedman 2010). Typically, science centers include a combination of interactive exhibits that invite and respond to visitors' actions and hands-on exhibits that do not offer interaction feedback but allow visitors to touch and handle them. In science centers, visitors are not regarded as passive recipients but acknowledged as actively involved in the acquisition of knowledge (Hooper-Greenhill 2000).

Wellington (1998) described two types of exhibits usually found in science centers: experiential and pedagogical exhibits. In experiential exhibits visitors learn something by relating bodily to physical phenomena, whereas in pedagogical exhibits visitors learn by being taught something, that is, by formal learning. The idea of experiential exhibits originates from the philosophies of experiential education emphasizing the importance of personal experiences for learning (Kolb, 1984; Dewey 2008a). This form of learning is informal in that it is promoted by the visitor's own reflections on her or his experiences.

Experiential exhibits are interactive exhibits "in which visitors can conduct activities, gather evidence, select options, form conclusions, test skills, provide input, and actually alter a situation based on input" (McLean, 1993, 93). Bitgood (1991) specified that interactive exhibits allow physical interaction in which the visitor's response to the exhibit produces a change in the exhibit, for example, lighting, sound, and objects' position. $\mathrm{He}$ distinguished between simple hands-on exhibits that allow the visitor to for example, touch objects, participatory exhibits that prompt a response and an outcome by comparing it with some other response or standard, and interactive exhibits that prompt a response which changes the stage of the exhibit. This change is generated by the visitor's actions.

We know from previous research that it is not possible to prescribe interaction behavior or outcome in experiential exhibits because visitors approach interactive, open-ended exhibits differently (Allen, 2004). Allen and Gutwill (2004) argued that multiple interactive features may overwhelm, disrupt, or displace visitors' attention and in the end disturb or prevent the visitor's experience. Dancstep et al. (2015) suggested that whole-body exhibits, compared to tabletop exhibits, each have their own strengths with respect to visitor experience measured by physical effect, attitude, scientific thinking, and memorability. In their study, immersive, whole-body interactive exhibits fostered slightly more positive attitudes particularly in relation to using the exhibits with others (social interactions), whereas tabletops held visitors' attention for longer periods of time and prompted more utterances and reasoning about the scientific phenomena compared to whole-body interactive exhibits. In regard to memorability, there were few differences between the two exhibit types. Dancstep and her coauthors summed up by emphasizing that we still need more research about immersive, whole-body exhibits.
Concerning social interactions, most studies have focused on the effect and outcome of the social interaction between visitors. Several studies investigated family groups and intergenerational social interaction in interactive exhibitions. These studies showed that grandparents and other caretakers were important teachers and facilitators for the visitor experience (Blud, 1990; Sanford, Knutson and Crowley, 2007; Gutwill and Allen, 2010). Others studied groups of children, also with the aim of understanding how they collaborate (Mcclafafferty and Rennie, 2012; Yoon et al., 2013; Piscitelli and Penfold, 2015; Skydsgaard, Andersen and King, 2016). Overall, these studies suggested scaffolding as essential in interactive exhibitions, provided through collaboration, digital augmentations, or posted questions.

The aim of this exploratory study was to extend our knowledge about one particular form of exhibit design at science centers, namely, interactive, whole-body, and collaborative exhibits. The goal was to investigate how a set of multiple exhibit features guided visitors to engage actively in exploration of the exhibition topics and make sense of the social whole-body interactions and transform their experiences into knowledge. The study investigated the visitors' experiences while interacting with the exhibits and the experiential quality of exhibit features:

1. How did the exhibit features guide visitors to engage collaboratively and interactively in experiential exploration of the exhibition topics?

2. How did the exhibit features guide visitors to make sense of the collaboration and interaction and transform experiences into knowledge?

The first research question addressed how the visitors reacted emotionally to the exhibit features and interacted with them and with one another. The second question explored the visitors' sensemaking regarding the lessons learned that may be distilled from the reaction, interaction, and conversation between the group members.

The remainder of this article is organized as follows: Theoretical Framework presents the theoretical framework. The case and research methodology is presented in Research Design. Findings covers the results on how visitors used and experienced the exhibition. Discussion and Implications discusses how the exhibit features and activities contributed and can be improved to support the visitor experience, and the research conclusions are presented in Conclusion.

\section{THEORETICAL FRAMEWORK}

In this section, we sketch the theoretical background of our study. We start with presenting our understanding of the concept of experience and how this understanding informed our approach to the experiential qualities of the exhibit features. Experiences are generated by direct contacts with the environment. Seminal for understanding the experiential qualities of an exhibit is, thus, the reactions and interactions of the experiencer to the surroundings. In the second part of this section, we present core elements of 
sociocultural theory to describe exhibit features which have distinct experiential qualities.

Experiences are never simple responses brought about by some identifiable stimuli. Experiences are situated. First, they occur in a specific situation and their occurrence depends as much on the situated actions of individuals as on their reactions to the situation (Dewey, 2008a; Jantzen, 2013). Experiences presuppose a doing as well as an undergoing by the experiencer. Second, the quality of new experiences depends on prior experiences and on the expectations to the situation that these have fostered. Prior experiences generate a norm on which the new situation is assessed (Kahneman, 1999). New experiences occur when the situation differs from this norm.

Experiences, therefore, imply two temporal dimensions. On the one hand, experiencing is instantaneous by being bound to the present in which something happens. This immediacy of experiencing is physiologically and affective in character. But on the other hand, "an experience" may be long-lasting by becoming memories of events having occurred in the past. "An experience" integrates the lessons learned from experiencing with existing information (the norm), hence leading to an increased or altered understanding of the world and/or oneself, which can be utilized in future experiences (Dewey, 2008b). This process is sensemaking and captures the learning dimension of experiencing. Thus, experiential learning occurs when the immediacy of affective changes is transformed into a higherorder purposeful action (i.e., meaning) that forms the basis of new know-how (Kolb, 1984). Learning is the lasting outcome of the museum experience and is the result of the combination of what takes place at the exhibit and what the individual visitor makes of it (Ansbacher, 1998).

In this respect, an experience is complex, coherent, and a whole that integrates physiological, emotional, and cognitive dimensions. Experiences, thus, balance immediacy (sensing) with permanence (memory), bodily (emotional and physiological) with mental (sensemaking) operations, and passivity (undergoing) with activity (doing) (Jantzen, 2013). This balance characterizes the whole-body experiences that experientially oriented science centers are aiming at. In assessing the experiential quality of the exhibits, we, therefore, look at three parameters: 1) visitors' affective reactions to the exhibits' features (i.e., their “undergoing”); 2) visitors' interactions with the exhibits' features and with one another (i.e., their "doing"); and 3) visitors' sensemaking regarding which lessons for life in general can be distilled from these reactions and interactions (i.e., the visitors' learning). An analysis of how exhibit features and activities are experienced, thus, requires a framework that captures the dialectic relationship between the human body and mind on the one hand and exhibit features on the other hand.

Inspired by Jakobsson and Davidsson's (2012) sociocultural approach to study science centers, we used the concepts of mediated action and mediational means as the framework for our analysis of how exhibit features engage visitors and guide them in the transformation of experiences into knowledge. Mediational means can be defined as all possible and accessible resources in a learning process. Mediational means include artifacts, meaning resources of the physical world, for example, stones or cultural or historical products originating from human actions, for example, bicycles, pots, and games, and human mediation referring to interhuman actions, for example, collaborative activities, discussions, and combats (Wertsch 1998). In this perspective, the collaborative, whole-body activities (situated experiences) should be understood as mediated actions. Wartofsky (1979) has introduced a categorization to describe artifacts. He divided man-made artifacts into three hierarchical levels: primary, secondary, and tertiary artifacts. Primary artifacts are physical tools facilitating the performance of activities, for instance, a hammer, a lamp, or a ball. Primary artifacts correspond to Wertsch' physical world artifacts. Secondary artifacts are representations or modes of action created to govern our actions, for example, instructions, recipes, and maps. The third category refers to imaginary worlds and is a kind of extension of the secondary artifacts developing and mediating information about the secondary artifacts and their related actions, for example, a kitchen in which we use knife and recipes.

This framework was helpful in two ways. First, the framework helped us to identify and describe the exhibit features, for instance, in the PULSE Exhibition's Bike Shed the visitors settled on the bikes (primary artifact) to ride to the beach (tertiary artifact). They watched the video screen (primary artifact) where a video (secondary artifact) informed them where they should go and who were in front on the trail. Second, the theory on the mediated relationship between visitor practices and exhibit features helped us to understand how the visitors reacted to the exhibit features, structured their interactions, communicated with each other, and made sense of the features. The analysis allowed us to answer our research questions how the exhibit features guided the visitors to engage in and interact with the exhibits, and how they supported the visitors in transforming and making sense of their experiences. We used the gained insight to discuss how features could be improved to optimize the visitor experience.

\section{RESEARCH DESIGN}

\section{Context}

The study took place at a large science center in Copenhagen that emphasizes experimentation through interactive exhibits. The context was the PULSE exhibition consisting of eight individual exhibits, each of them consisting of multiple features to support visitor's experiential learning (Falk and Dierking, 2013). These eight exhibits were separate spaces for visitors to enter. Together they formed a square with a check-in and information point in the middle. The exhibits represented traditional parts of a family home and core family activities in Western societies, for example, a kitchen for cooking, a living room for watching television, a bathroom to be cleaned, and a field for playing a ball game together or a bike shed. The exhibition was, thus, a playful rendition of everyday chores.

The exhibition was to a large degree built on experiencing through physical tasks in whole-body, immersive exhibits with 
(intergenerational) collaboration as the prominent scaffolding feature. The visitors were encouraged to be physically active. They were, for instance, encouraged to crawl along the hallway, tilt family members off the living-room sofa, play "Earth is poisonous" in the kitchen, or dance in the bathroom. The exhibition's narrative focused on illustrating how families can easily do exercise and increase their heart rate while performing everyday family activities. Each exhibit revolved around one or several biological phenomena, for example, balance, coordination, speed, and suppleness, with the aim to show their importance for physical activity. The collaborative principle was reflected in tasks requiring cooperation, in games, and in the mandatory group formation at the check-in. The check-in took place at eight interactive welcome interfaces situated at the central square, the "Middle." During check-in, the group registered with a group name and an email address, and a site was created for each group to collect and store data about their activities. These data consisted of photos taken at each exhibit. After having checked in, the group could start its journey through the exhibition. The order of visits to the eight exhibits was random. Any order was allowed, but to start the activity all group members had to check in at the exhibit check-in stand. Operational instructions were provided by instruction labels appearing shortly as part of the exhibit check-in procedure both at the check-in devices and the wall screens. Scientific information about the biological phenomena of interest were primarily provided by quizzes and some few fast fact labels about the biological phenomenon of interest (e.g., about burning energy or on heart rate). The feedback labels with scores and fast fact labels appeared on separate screens placed in the exhibit rooms. Personal pilots were circulated in the exhibition sporadically with the main purpose of solving technical problems, for example, due to crash of screens and videos. For a video presentation of the exhibition, see Experimentarium (2021).

The eight exhibits consisted of a combination of mediated actions and primary, secondary, and tertiary artifacts (mediational means). The mediated actions consisted of tasks, for example, the task of switching off flashing lamps without touching the floor in the Balance Kitchen or biking as fast as possible to the beach in the Bike Shed. Each exhibit was composed of a room that the visitor entered, for example, a kitchen with pots and towels or a hallway with dropped coats, shoes, and school bags. Each room had a set of tools, a check-in device to register groups, and buttons to be pressed as part of the visitor activities. The room, its artifacts, and the tools constituted the primary artifacts. The labels and other guiding elements (e.g., sounds, music, and light bulbs) comprised the secondary artifacts instructing or supporting the activities. The music supported the dancing in the bathroom (or sounds the switched off lamps in the Balance Kitchen). A well-known fictional character was used to present the activities, for example, in the Dance Bathroom where the well-known children's TV star guided the visitors through the dancing task. Labels were used to instruct on how to carry out the activities, communicate scores, encourage the visitors, or inform about the scientific phenomena. Videos guided the visitors through the tasks in the Bathroom, Bike Shed, and the Fence Jump. The tertiary artifacts were built into the tasks providing a fictional story, for example, the child's play "the Earth is poisonous" in the Balance Kitchen and a gaming element, for example, competing with other groups in the number of switched off lamps without touching the floor or arriving in front of the others at the beach. The gaming dimension could be inter-group (e.g., which group earns most points in the Balance Kitchen) or intra-group (e.g., which group member is able to jump highest in the Fence Jump). The fictional storyline enchanted certain aspects of family life and its routine chores, for example, the Dance Bathroom or the Rodeo Lounge. In Table 1, we present the eight individual PULSE exhibits and their exhibit features.

\section{Methods and Participants}

Our study explored the visitors' experiences with the exhibition using data from walk-alongs (walking interviews) with 34 visitor groups comprising a total of 108 visitors (Kusenbach, 2003; Evans and Jones, 2011). Three external researchers carried out the ethnographic walk-along study over four months from November 2015 to March 2016 (Skov et al., 2019). All the walks were group walks. The units of analysis were 13 family groups (23 adults and 25 children) and 21 groups of primary school students (60 school children). Table 2 provides an overview of the visitor groups.

The families were day-trippers that the researchers, working independently, contacted at one of the two entrances of the PULSE exhibition. When inviting the visitors to participate, the interviewers gave an oral presentation of the research project and handed out consent letters. As an incentive, the visitors who agreed to participate were offered free drinks in the café. The participants were told they were free to decide their pace and route through the special exhibition. The school groups were invited to the science center to enjoy a free visit and participate in the study. The groups were formed by the accompanying teachers. The students attended fourth and sixth grade in the Danish primary school system and were 9-10 and 11-12 years old, respectively. Consent letters describing the project and the walk-along method were signed beforehand by the parents of the invited school classes. The students were also offered free drinks in the café for their participation. While some participants explored all the exhibits, others only explored a few. The durations of the walk-alongs ranged from 10 to $72 \mathrm{~min}$, with an average of $38 \mathrm{~min}$.

\section{Data Collection}

The interviewers opened the walk-alongs with factual, demographic questions on the participant's age, nationality, motivations, and expectations, and whether she or he had a professional or layman relationship to health and physical activity. During the walk-alongs, the participants were stimulated to comment on their experiences and viewpoints on the exhibition. The interviewers used a short interview guide with three themes to inspire and prompt informal talks. These themes touched upon the visitors' perceptions, emotions, and engagement. The interviewers concluded the walk-alongs with follow-up questions on themes from the interview guide and issues that emerged during the walkalongs. 
TABLE 1 | Description and photo of the Middle and the eight Pulse exhibits.

\section{Exhibit \\ Interaction and features}

The Middle

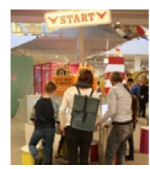

The Balance Kitchen

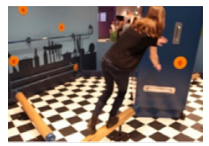

The Rodeo Lounge

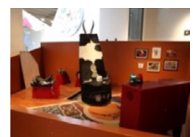

The Dance

Bathroom

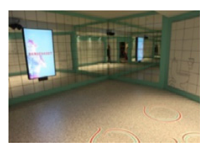

The Obstacle Hallway

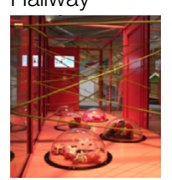

The Energy Roller

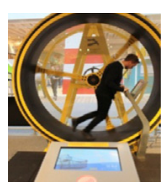

The Bike Shed

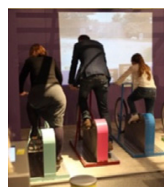

The Fence Jump

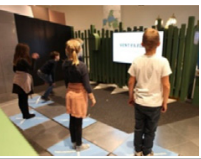

The Ball Cage

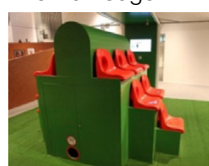

Here, the visitors form groups and register by entering a group name. During their visit they can choose to watch photos taken during their activities, select photos to be sent to their email, and participate in a quiz where they get facts and information about key concepts.

\section{Options for activity}

- Allow the visitors to form groups and register by name and email.

- Participate in the PULSE quizzes and gain medals.

- Get facts and information about key concepts. For example heart rate, balance, and fitness.

- Watch photos taken during their activities at the 8 exhibits.

- Select photos to be sent to email.

- Provide experience that you need a combination of balance, speed, and muscle strength to gain points.

- Provide experience that you can play the "Earth is poisonous" everywhere. kitchen walls so the visitors must balance and climb the kitchen furniture to turn off the blinking buttons by touching then. They gain one point for each switched off button. If a member touches the ground all points are lost.

This exhibit is inspired by the "wild bull" concept. In the lounge the visitors collaborate by pulling horse reins to kick off the group member sitting in the "best chair" in the living.

- Provide a task where the group members collaborate.

- Provide a dialogue about the members' (bad) habits.
The exhibit builds on a Wii Play. Here, the group members dance to disco music. A visual instructor guides them through cleaning movements and rates their effort. If they move insufficiently, they must repeat the cleaning moves.

This exhibit is an obstacle race. Here, the visitors must crawl and fight their way through the stacks of shoes, jackets, and bags that have been dispersed in the hallway. They must all get through the hallway as quickly as possible to get the best time.
- Provide that the whole group dance.

- Provide the feeling how nice it is to move.

- Provide experience that you can dance and have fun everywhere.

- Provide the experience that dance challenges blood circulation, speed, and movement.

- Provide experience that you need balance and mobility to crawl and climb.

- Provide experience that it is a fun and good exercise to crawl and climb

- Provide the experience that you can make crawling lanes everywhere.

- Show the relationship between physical activity (energy burning) and food energy (energy record).

- Provide the experience of collaboration.

- Provide coordination of physical activity. chocolate, and Coca Cola in the visual super market. Carrots are heatt therefor cheap while a Coca Cola is expensive.

This exhibit is a bike race. Here the group members are invited on a bike trip to the beach. Who will be first to swim in the sea? When the members arrive at the beach, the handle of the bike measures their heart rate to see how quickly each member's pulse falls. For which member is most fit?
- Provide insight into heart rate-it increases with movement and decreases when we relax.

- Provide insight into the concept of fitness. Some members have better fitness than others.

- Provide an experience that biking is a good, everyday exercise.
In the Fence Jump the group members are instructed to jump as high as possible. They get the chance to make two jumps. Both jumps are filmed, so the participants can see how and how high they jump at each try. Between the jumps they are instructed by video how to improve their jumping.
- Provide the experience that you need muscle strength, coordination, and technique to jump high.

- Provide a shared experience that it is fun to jump.

- Provide an opportunity to compete-who has the best jumping technique?

Here there is a stall-tower with a hole in each seat that lights up in no particular order. Balls are continually jumping out from the two ends and you gain points by putting these into a lighting hole. In order to get as many point as possible within two minutes the members must collaborate and coordinate. The exhibit is inspired by hand ball and basketball.
- Provide an experience that ball games require precision, speed, strength, suppleness, and dexterity.

- Provide the experience that ball games are both an informal activity and an organized, serious game.

- Provide the insight that ball games also require collaboration and strategy. 
TABLE 2 | Overview of composition of visitor groups.

\begin{tabular}{|c|c|c|c|c|}
\hline $\begin{array}{l}\text { Walk- } \\
\text { along }\end{array}$ & Family groups & $\begin{array}{l}\text { Walk- } \\
\text { along }\end{array}$ & School groups & School \\
\hline 3 & $\begin{array}{l}\text { Two female friends visiting with their children. One mother with a pair of } 7 \text {-year old twin boys and the } \\
\text { other mother with one boy aged } 7\end{array}$ & 1 & Three boys $(10,10,10)$ & A \\
\hline 4 & Mother and daughter (11) visiting with mother's brother, his wife, and their baby & 2 & Three girls $(10,10,10)$ & A \\
\hline 5 & Mother and daughter (9) & 9 & Three boys $(9,9,10)$ & $\mathrm{B}$ \\
\hline 6 & Mother, father, son (14), and daughter (7) & 10 & Three girls $(10,9,9)$ & $\mathrm{B}$ \\
\hline 7 & Father with son (11) and male friend of son (12) & 11 & $\begin{array}{l}\text { Two girls }(9,10) \text { and two boys } \\
(9,9)\end{array}$ & $\mathrm{B}$ \\
\hline 8 & Two female friends visiting with each one child: two girls (4 and 9) & 12 & Three girls $(12,12,12)$ & A \\
\hline 14 & Mother visiting with three children: two girls 9 and 16 ) and a boy (10) & 13 & Two boys $(12,12)$ & A \\
\hline 15 & Two female friends visiting with each one child: two girls 4 and 9) & 16 & Three girls $(10,10,10)$ & A \\
\hline 18 & Mother and son (10) visiting with aunt & 17 & Two girls $(10,10)$ & A \\
\hline 19 & Grandparents visiting with their grandchildren: two girls (5 and 13) & 21 & $\begin{array}{l}\text { Two boys }(10,10) \text { and one } \\
\text { girl (10) }\end{array}$ & $\mathrm{C}$ \\
\hline 20 & Two sisters (24 and 26) visiting with their younger cousin (12) & 22 & $\begin{array}{l}\text { Two boys }(10,10) \text { and one } \\
\text { girl (10) }\end{array}$ & $\mathrm{C}$ \\
\hline 30 & Mother with 3 sons & 23 & Three boys $(12,12,12)$ & C \\
\hline \multirow[t]{9}{*}{31} & Mother, father and two daughters (no age indication) & 24 & Three boys $(12,12,12)$ & A \\
\hline & & 25 & Three boys $(12,12,12)$ & A \\
\hline & & 26 & Two boys $(10,10)$ & A \\
\hline & & 27 & Three boys $(10,10,10)$ & A \\
\hline & & 28 & Three boys $(10,10,10)$ & $\mathrm{C}$ \\
\hline & & 29 & Three boys $(10,10,10)$ & $\mathrm{C}$ \\
\hline & & 32 & Two boys $(9,9)$ and one girl (9) & $\mathrm{B}$ \\
\hline & & 33 & Three girls $(9,9,9)$ & $\mathrm{B}$ \\
\hline & & 34 & Three girls $(9,9,9)$ & $\mathrm{B}$ \\
\hline \multicolumn{2}{|c|}{ Total: 13 family groups with 22 adults and 25 children } & \multicolumn{3}{|c|}{ Total: 21 school groups with 60 children } \\
\hline
\end{tabular}

The walk-alongs were tape-recorded by two wireless microphones, one placed on the researcher and the other on a member of the group, capturing the conversations, sounds, and noises in the exhibition hall. After the walk-alongs, the interviewers made structured notes on the route, speed, moods, interactions, collaboration, and conversation between group members.

The principal reason for choosing the walk-along method was that this method, originally developed in urban geography, allowed the researchers to accompany visitors on their natural outings, track their routes, and capture their immediate reactions, actions, and emotions in the instant of interacting with and experiencing the exhibits (Kusenbach 2003). Additionally, we chose the walk-along method with the purpose of combining the advantages of the walking interview with the classic sedentary interview. Studies by Evans and Jones (2011) showed that walkalong interviews triggered more location-specific data, whereas the classical interviews more often concerned more general topics like the neighborhood or issues related to the interviewee's life. At the end of the walks, we found a place in the periphery of the exhibition where we carried out the follow-up interviews, preferably sitting quietly with the visitor group.

\section{Data Analysis}

During the first step in the data analysis, the interviewers listened to the tape recordings several times to recall the walk and generate a list of emerging themes for each walk. The interviewers separately conducted this coding as an open, thematic analysis (Bryman, 2016). During the visitors' walks there were long breaks with no conversation between the group members (and the accompanying researcher) because the group was physically active and fully concentrated in solving the physical task, for example, alternately crawling through the hallway. Here, the sounds of visitors' gasping, moaning, and cheering are important in order to recall the emotions, efforts, enthusiasm, or exhaustion, which were part of the visitor's experience. By hearing audio recordings, each researcher revived and recalled the walk. Conversations among group members were transcribed. This first analysis resulted in an experience map that was prepared for each walk (Temkin 2010). The map consisted of the themes that emerged during the analysis and a textual description of the route of the visitors' journey, actions taken, conversations between group members, social interaction, and challenges in the visitor interaction. The map also included a list of the main experiences and moods that emerged during the analysis. By main, we mean the visitors' experiences and moods that stood out and by observation were most notable among the reactions to the exhibition. Table 3 shows an example of an experience map.

The maps constituted a checklist in the later analysis where the researchers compared and discussed maps and coding results across the walk-along groups. To discuss results across the walkalong groups and determine recurrent themes paying particular attention to commonalities and differences within the study sample, the researchers applied a hermeneutic analysis strategy by relating parts from the observation notes, soundtracks, transcribed conversations, and experience maps to the whole visitor experience and vice versa (Schwartz-Shea and Yanow, 2012). The final analysis focused on the three types of artifacts functioning as mediational means (Wartofsky, 1979; Jakobsson 
TABLE 3 | Experience map for walk-along 19.

\section{Participants}

\section{Walk-along 19}

Family group 05.12.15 Marianne Lykke 4 visitors: grandmother (70), grandfather (68), girl (13), and girl (5) from Copenhagen area First visit to Plus.

\section{Themes}

\section{Instruction and preparation}

The family oversaw at several occasions the instructive labels how to operate the features: check-in, Rodeo Lounge, Energy Roller. Further there were several instructions that they did not understand. They learned how to operate the features by looking at other groups while waiting. They also used the waiting time to plan their interaction.

Collaboration

The family collaborated in understanding and operating the features.

Roles

The children decided the route in the exhibition, while the adults had the coordinating role. The grandfather instructed the others and encouraged them when difficult or tough. The adults created team spirit by highlighting the qualifications of the participants. The eldest girl was also active in understanding how operate the features.

Dialogue sensemaking

The dialogue concerned exclusively how to operate the features. Only at the Bike Shed the grandfather commented on his fitness and how it is shown through the pulse. The comment did not trigger further discussion.

\section{Experiences}

Active participation, collaboration, interactivity, gaming element, and attention on fitness

Moods

Happiness, engagement, concentration, and patience

\begin{abstract}
Visitor journey
The group does not discover the check-in. They walk around a bit perplexed and try in vain to get started. At the end I guide them to the check-in, and they register without problems. The eldest girl wants to start out with the Rodeo Lounge. There is a queue, and they decide to start with the Dance Bathroom. Here is also queue, and they line up. They use the waiting time to look at and learn from the other visitors. They comment on the active visitors. "Dammit she is good." "This is a bit youthful for us." The grandparents laugh disarmingly. "Can we do this?" The smaller child gets impatient. They have not noticed the timer, but use it at once when I tell them. "It will not take long." "Ok, are we all checking in?" When they are ready, the grandfather instructs. "Now we should prepare." "We must say on the spots." "Do as the girl." They laugh "Waw it has to be quick." Afterward they agree that it was fun. "It is built as a with play?" They all participate actively in the dance. They laugh and express that it is nice to move and loose breath. At the Rodeo Lounge the grandfather build up an atmosphere and read aloud the instructions. They have to check-in twice. The small girl will sit in the chair. She soon loses the patience and skip. The eldest girl takes over the chair, and the others makes ready at the "horses." They do not understand that they need to pull the rein. I have to explain what to do. "Ah it is us who need to move" They laugh. They do not see the instruction labels at the television screen. After they walk to the Energy Roller. They have to wait again ad use the time to watch and make a plan. The grandfather encourages the group. He uses the feature that they can "buy" a cola explains the feature. He keeps on the narrative. He encourages them to collaborate. "I need replacement". They work hard and help each other to keep the roller moving. They make turns. The grandparents help pushing the roller when the girls work. They do not discover that they can "buy" food. They find it very motivating that they can transform energy to food. They "buy" three colas with great pleasure. "We are very good." Then they try the bike shed. They have to wait and plan while they wait. They are all four active. The small girl cannot step the pedal. She cries and goes to her grandmother. The grandparent misses a real pedal, and they all miss a seat. They follow the instructions, and keep the hands on the handle. The grandfather comments that his fitness is bad. "Ah, my pulse is going down slowly." He comments on the technical and biological details. They do not visit more exhibits, because the small girl runs out of the exhibition. The others follow her "she is too small. This not for her."
\end{abstract}

and Davidsson, 2012), relating and exploring visitors' engagement, and sensemaking with the artifact types.

\section{FINDINGS}

The analysis of the data showed that six circumstances affected the ways in which the visitors engaged with and made sense of the exhibit features: 1) sensory attraction; 2) planned collaboration; 3) becoming (too) immersed; 4) commitment and perseverance through gaming; 5) child's plays as invisible instructors, and 6) situated scientific information. This section describes these circumstances as well as how the exhibit features functioned as mediated actions and mediational means for visitor engagement and sensemaking.

\section{Sensory Attraction}

The scene of the exhibition with eight individual exhibit rooms, each clearly defined by walls or fences and a specific color, had a strong visual effect, and attracted the incoming visitors' attention when approaching the exhibition. Particularly, the Rodeo Lounge and Energy Roller appeared to be both recognizable and interesting to the visitors. The visitors' reactions were generated by the combination of familiarity with the stories of rodeo riding and hamster wheeling and surprise with the different structure of the actions, for example, a rodeo with three horses and a bull in form of a chair, and a hamster wheel where it is the visitor who must do the running. Also, the sounds and the human mediation in the form of crowds and a hectic atmosphere with collaborating visitors shouting, laughing, hopping, and dancing drew attention and interest. The joyful pop music from the Dancing Bath and the visitors' cheering provided a welcoming and engaging atmosphere. Likewise, the physical tasks caught attention when entering the exhibition again, caused by this combination of familiarity with, for instance, ball games and bicycling and wondering what people were doing, because the activities were slightly different compared to the ordinary way in which these routines are performed. Contrary to the scene, story, and sound features, some of the tasks provided both positive and negative reactions; for instance, many boys felt shy about the task of dancing in the Dance Hall, and several adults were reluctant to participate in physically demanding activities. While some expressed worry ("Wow, this is difficult. Do you think that I can manage?", girl, 9 years, walk-along 5) others expressed great enthusiasm, for instance, when they realized that they were going 
to play ball in the Ball Cage. Only the combined check-in and information point in the middle of the exhibition did not attract attention. Its scenery of gray computer screens, the typing tasks, and the visitors' concentration and low speaking were not specifically interesting or striking. The findings tell us that sensory means have attraction power (Falk and Dierking 2013). Visitors were attracted by the inviting dancing music, laughing, and cheering people, and physical landmarks like the Hamster Wheel. Also, the child's play stories that provided a feeling of familiarity and nostalgic childhood memories had attraction power. It seemed that the tertiary artifacts in form of the very concrete and at the same time emotional child's play stories contributed better to attracting visitors compared to the other tertiary artifacts, such as, the fictional storyline in form of the family home, kitchen, bathroom, and the imaginary tasks of cleaning the bathroom and biking to the beach.

The scene of the exhibition with the eight shielded rooms caught the visitors' attention and made them curious to enter the rooms and discover what was going on. Similarly, the Rodeo Lounge and Energy Roller were visual landmarks standing out at the scene. Also, the sounds of pop music and countdown and the human mediation in the form of visitors shouting, cheering, and laughing drew attention and interest by sensory means. Summing up, the different examples illustrate the attraction power of sensory means.

\section{Planned Collaboration}

All the groups seemed to understand that the order of the exhibits was optional and random. The visitors chose strategically the exhibits they found interesting and planned their routes with regard to the crowds and waiting time, thus appreciating the open structure of the exhibition. Many groups used the timers on the local check-in screens to plan their route (e.g., "They have just started over there. This will finish soon. We'll start here" (girl 12 years, walk-along 12 ).

In line with previous studies, the (grand)parents took the role of facilitators in the family groups explaining what was going to happen (Blud, 1990; Sanford, Knutson and Crowley, 2007; Gutwill and Allen, 2010). They cheered on the children and ensured that they completed the activities. In most school groups, the children acted on equal terms, and altogether helped each other to understand the activities, cheered at and encouraged each other. As seen in the studies by Skydsgaard, Andersen and King (2016), they discussed and shared their feelings and thoughts. In family groups, the members explicitly divided the tasks among one another; in most school groups the cooperation was intuitive and tacit. In both these types of visitor groups members took turns, for instance, in the physically demanding Energy Roller.

Both family and school groups highlighted the joint activities and emphasized in the post interviews that the need for collaboration and coordination was an important feature of the visit confirming that museum visits are motivated by a combination of social, recreational, and learning reasons (Falk and Dierking 2013). The social interaction did not only happen within a group. The groups also helped each other, mostly with advice on how to operate the interactive features or how to gain better scores.

\section{Becoming (Too) Immersed}

Most visitors were very concentrated on planning and carrying out the physical activity. They barely had time or cognitive resources to talk about the scientific topics. So, in general the groups did not take the time to talk together, read the few explanatory exhibit labels, or take the quizzes. Only three groups out of the thirty four went back to the Middle to answer quizzes related to the exhibits. Eight groups used the opportunity to collect photos. The findings match findings from Dancstep et al. (2015) that whole-body interactive exhibits have a diminished intellectual engagement compared to hands-on exhibits that also held the visitors' attention for a longer period. The family groups did not discuss the exhibit themes more often or more comprehensively compared to the school groups, contrary to findings by Crowley et al. (2001). Actually, it appeared from the conversations and the follow-up interviews that as the school children had been introduced to the overall exhibition theme before the visit, they paid attention to the scientific themes of the exhibition.

The findings showed that the whole-body activities that required both physical as well as social coordination and concentration took the visitors' full attention. The visitors were completely absorbed in jointly understanding and coordinating the activities so that they could complete the activities and games. The exhibition's goal of physically engaging and motivating the visitors to physical activity was fully achieved, while the physical activity at the same time was an obstacle to the exhibition's second goal of getting visitors to reflect on and talk about the importance of physical activity for their health and well-being. Correspondingly, the free order of activities had a motivating effect, just as the free order at the same time required planning and took the visitors' attention.

\section{Commitment and Perseverance Through Gaming}

Some groups took up the gaming element of the activities ("Hurry up! There is a ball. We got 30 points", boy, 9 years, walk-along 9). Other groups saw them as play ("this is fun. You are not allowed to touch the ground. You must run around and press a lot of buttons. And if you touch the ground, you must start all over again”, boy, 9 years, walk-along 11). Some groups barely noticed the scores and points. In general, family as well as school visitors found point scoring to be engaging and fun, but very few saw competitions as a motivating feature in itself. When asked in the post interview, a schoolboy explained: "Of course, we check how many points the other groups get. We were better than the girls at the Dance Bath, haha. What I like most is when it is the team that must do well" (Boy, 10 years, walk-along 1).

While the competitive element of comparing points across visitor groups did not motivate or stimulate visitor interaction, the points stimulated the visitors to try out the activities a second time to improve their results. As such, the gaming feature and points had the important role of motivating repeat interaction, increasing holding time, and intuitively and unconsciously engage the visitors to work with their physical techniques and collaborative coordination. 


\section{Child's Plays as Invisible Instructors}

The activities were intuitively understandable for the visitors. The tasks themselves were simple and clear, for example, turn off lights, dance, and put balls in a hole. This understanding was furthermore well supported by child's plays that provided an immediate understanding of how to interact by activating previous experiences. In the Ball Cage, knowledge of ball games and scoring guided the visitors to throw the ball into the goal to gain points. In the Fence Jump, the visitors were guided by their knowledge of play in for example, school yards or gardens. Likewise, in the Dance Bathroom, the visitors were guided by the Wii Play in form of the instructing video and the story that we sing and dance in the bathroom. The understanding was also supported by a clear relationship between the task and the game, for example, between switching off blinking lamps and earning points. The child play "Earth is poisonous" supported the understanding that the visitors should balance the kitchen equipment to fulfill tasks and dramatized the game by introducing the rule that you lose all points if you touch the floor. In these exhibits, the visitors' interaction was supported by a clear relation between the task, game, and story.

In contrast, the visitors had problems in understanding the interaction in the Rodeo Lounge, Obstacle Hall, and Bike Shed due to unclear relationship between the task, story, and game. They did not grasp the more contrived stories, for example, in the Rodeo Lounge where group members had to kick one of their companions away from the sofa and the television set to get the person concerned to exercise instead. Similarly, in the Obstacle Hallway the relationship between task and game was unclear. In the Obstacle Hallway, the visitors did not understand either the task or the relationship between the task and the game. The visitors were not sure whether the aim was to traverse the hall as fast as possible or to avoid touching the rebound. In addition, they did not grasp whether they gained points individually or as a group. Also, in the Rodeo Lounge, the task caused divergences as the visitors did not realize that they needed to pull the interactive reins to kick off the person in the chair. Also, here the mismatch occurred because the relationship between the task and the game was unclear for the visitors. In the Energy Roller, the visitors in general understood the task of running the wheel to "earn" kilojoules as a token of the amount of energy burned. The aim of the story was to raise the visitors' awareness of differences in kilojoules between various types of snacks, for example, carrots or chocolate bars. Running the wheel was a physically quite demanding activity apparently motivating many visitors to attempt to earn points for "buying" the more "expensive" rewards (e.g., a chocolate bar which cost more kilojoules than the carrot). In this respect, the game came to contradict the story. In a similar vein, many visitors did not see the relation between the story and the game in the Bike Shed. The task in this exhibit was to bike on a home trainer and the story (supported by a video) was to try to be the first to reach the beach by bike. The game, though, was about who was able to decrease her or his pulse most significantly after having reached the beach. During the countdown the visitors had to hold their hands on the handles to see how the pulse decreased. Many visitors overlooked this aspect and left the exhibit before the countdown was over and the game had ended. In this the story contradicted the game. In all, the findings show how the child's play intuitively guided the visitors' understanding of the exhibits leveraging the visitors understanding of the task and the game.

\section{Situated Scientific Scaffolding}

Only a few groups seemed to perceive and reflect on the biological phenomena presented in the exhibits, for instance, the importance of balance and mobility in the Balance Kitchen and the Dance Bathroom. An example is how the mother and daughter in walk-along 5 reflect and talk about pulse:

"Keep the hands at the handle. So ... as quick as your pulse falls .... You can see your pulse down there. It is 134, right?" (mother).

"Is it very high?" (girl, 9 years).

"Yes, but you are a child. It should actually register that you are a child and I am a grown-up" (mother).

[Bell rings and the pulse measurement is completed].

"Ok, my pulse decreases with 53 beats while I was relaxing. Yours only decreases 20." (mother).

"Aha" (girl, 9 years).

"So, in theory, it should mean that I am in a better condition compared to you, but I do not think so" (mother).

In the Energy Roller some visitors used the possibility to transform the earned kilojoules into food, but none of them talked about the relationship between energy intake and energy burning for keeping, gaining, or losing weight. The groups talked about their (lack of) fitness in the Bike Shed. For instance, the following dialogue occurred during walk-along 8 :

"Man, it is hard. Wow, mine is high-see my pulse" (mother).

"My heart is beating like hell" (boy, 10 years).

"My legs are trembling" (girl, 10 years).

However, only a few considered the importance of the heart rate and how we can use it to measure fitness by how quickly one restitutes after intense activity. Generally, the exhibition was not successful in stimulating recognition and conversation among the visitors about the importance of specifics of physical activity, for example, heart rate, burning energy, and muscle strength. The collaborative planning and degree of whole-body interaction took the visitors' attention. Only in the Fence Jump the integrated video instructions (a secondary artifact) on how to improve jumping techniques stimulated visitor conversations about the biological phenomena. Here, the video that guided the visitors through the jumping and provided hints on how to jump higher was successful, because the mediation and explanations appeared as part of the activity, giving the visitor time to read and reflect. Consequently, many group members started encouraging one another to improve their jump by utilizing their body more efficiently.

\section{DISCUSSION AND IMPLICATIONS}

We started our analysis by asking how exhibit features supported the informal, experiential visitor learning in a whole-body, collaborative science exhibit and which features could be improved. 
Our findings point at three issues to consider in exhibit design. We use the three parameters of experiential learning derived from Dewey (2008a) and Jantzen (2013) to structure the analysis into how the visitors engaged with the exhibit features, how the visitors' reacted physiologically and emotionally to the features, and how they were motivated to interact cognitively with these means and actions and hereby explore the exhibit topics. Next, we analyze how the visitors made sense of their engagement with the exhibit features. In the analysis we use the Wertsch (1998) framework of mediated actions and mediational means (physical artifacts and human mediation) and Wartofsky's categorization and primary, secondary, and tertiary artifacts to guide the analysis.

First, we must emphasize that togetherness, the need for collaboration and coordination, and the shared physical activities were key motivations for visiting the exhibition. A mother in a family group explained "It is the social experience with our family that is central, not the learning. The exhibition is perfect because it is neither easy nor difficult, and it is good that you can try some things to increase your heartbeat" (Mother, Walk-along 6). At the same time both types of visitor groups emphasized the learning elements during the post-interviews and were very clear what they had learned from the exhibition, that is, "It is harder to exercise than I thought. You need both balance and to think quickly" (Boy, 10 years, walk-along 9) and "You must exercise. You must stick together. You need to collaborate in the Ball Cage" (Girl, 9 years, walk-along 11). This is in line with a previous research that science center visitors emphasize social interaction as a key motivation (Falk and Dierking, 2013). However, compared to previous studies, the visitors placed extra emphasis on the fact that most exhibits required a high degree of teamwork to function optimally. The need of strategic coordination and cooperation were of great importance to the visitors.

As for the wish to engage visitors and make them react physiologically and emotionally, the data gathered through observations during the walk-alongs showed that visible landmarks, inviting dance music and other sounds, recognizable play activities, and human mediation in form of high-spirited collaboration were able to catch the visitors' attention and generate a diverse set of reactions, physiologically (enthusiasm and arousal) as well as emotionally (enjoyment and anxiety). Both happy and anxious expectations engaged and drew the visitors to the exhibits. The findings suggest that the sensory means captured the visitors' curiosity intrinsically and motivated visitors to approach the exhibition (Csikszentmihalyi and Hermanson, 1995).

Concerning experiential interaction and exploration, the clear tasks and close relationship to games and the wellknown script of child's plays (i.e., the stories) were successful in activating the visitors. The combination of physical activity, gaming, and recognizable stories provided engagement as well as structure to the task and served, hereby, as cognitive guidance in how to interact with the primary artifacts and carry out the tasks. The findings further showed the need for a conceptual coherence between the task, game, and story. The illogical relationship between the game and the story in the Energy
Roller and in the Bike Shed and between the story and the task in the Rodeo Lounge and the Obstacle Hall generated interaction problems. In these cases the connection between primary and secondary artifacts on the one hand and tertiary artifacts (the game script and story world) on the other hand was unclear (Wartofsky 1979). These mismatches caused not only confusion but also made visitors miss important aspects of the exhibition's intentions. These findings confirm previous research that storytelling and narrative are important guiding design principles (Murmann and Avraamidou 2014; Skydsgaard, Andersen and King 2016) and are also in line with the Shaby et al. (2017) point that recognizability and guidance through well-established scripts are essential for intuitive, uncomplicated interaction and exploration. However, the findings also stress the importance of close relationship and coherence between the different exhibit features, hereby supporting Allen (2004) notions of conceptual coherence and immediate apprehendability. The visitors understood the purpose of the interactions immediately due to the wellknown child's play, but they did not recognize the intended themes when there were no clear, precise relationship and conceptual coherence between the multiple features.

The child's play as tertiary artifacts increased the engagement by moving the actions away from the school's formal learning setting to informal leisure and play. The playful approach further meant that the game's point scores were primarily used as an intrinsic motivation within the visitor group to try the activity once more to see if they could improve their effort and scores. Hereby, the extension and transformation of the task into play and the game stimulated the visitors to work with and improve their physical techniques and coordination in the group.

When it comes to sensemaking, the analysis showed that, due to the physically demanding activities and the required social collaboration, the visitors were not able to engage in in-depth discussions of the exhibition's scientific themes. In most cases the awareness of the significance of physical ability and coordination was unspoken between the participants, but it was clear through walk-along observations and some few visitor conversations that the participants sought to learn from their whole-body experiences and tried to improve their physical activity when trying out the exhibit task a second time. The findings are indications of situations in which visitors learned by relating bodily to the physical phenomena by physically trying out and improving their movements and coordination and hereby recognizing the importance of leg position for a good starting point for a jump in the Fence Jump. As such, the findings support the general believe that immersive, whole-body experience may be capable of enhancing visitor learning (Wellington, 1998; Gilbert, 2002). As in Dancstep et al. (2015), only few visitors expressed their reasoning verbally, but they showed their sensemaking when trying to improve their jumping techniques. Yet again, these findings demonstrate the importance of a conceptually coherent exhibit design with clear connection between lines of reasoning, for example, you can jump higher if you combine coordination and muscle strength (Allen 2004).

In several of the exhibits the supporting instruction and scientific information were incorporated into the activity. This 
worked especially well in the Fence Jump and Dance Bathroom, where the instructions on how to use the body to jump or dance were integrated naturally into the interaction by video films. In between the jumps and dance exercises a small video instructed how the visitors coordinating their movements can use their muscles more efficiently. In the Dance Bathroom the instructions were conveyed by a human mediator, a well-known children's TV character, that instructed the visitors by showing and explaining the movements. In the Fence Jump the instructions were made by a combination of textual guidelines and photos of a mother showing the movements to improve the jump. The findings tell us that integration of instructing labels that inform about the scientific subjects (secondary artifacts in Wartofsky's categorization (1979)) into the interactive process could be one way to support the visitors' understanding and sensemaking. Science centers have long relied on human mediation and informal docents to help guide visitors' experimentation (Gutwill and Allen, 2010). These findings indicate that future studies should focus on examining in detail the effect of video instructions integrated into the experience and how to convey these instructions, that is, by video films or textual and graphical means. Another solution to support the visitors' conversations and exploration of the scientific topics, in line with previous research, may be to integrate question labels or quizzes as interactive labels inviting the visitors with question-and-answer options, and to add a label at the entrance of the exhibition introducing the big idea, that is, a clear statement stressing what the exhibition is basically about (Gutwill and Allen 2010; Serrell 2015). A third solution could be to provide access to the quizzes in the email with selected photos that is sent to the visitors after the visit, as the visitors may have better time and cognitive surplus after the visit to talk with one another about the experience and the scientific topics. With this solution, it is considered that the visitor's experience consists of two temporal dimensions (Dewey 2008b; Jantzen et al., 2011). First, the visitor interacts with exhibits and has an experience, and then the visitor assimilates the experience, whereby previous experiences are affected. When we send the quizzes and pictures to the visitors after the visit, we seek to extend the visitors' inquiry and sensemaking by providing time for reflection and new questions, and for production of new ideas and knowledge (Ansbacher, 1998). Post-interviews by Lykke and Skov (2020) with family visitors three month after a visit to an interactive science exhibition showed that the interviewed families could retell the visit in detail, just as they told how they had tried similar activities and learned about similar topics after the visit, at home as well as at other science centers. The post interviews also showed that the degree of understanding and learning differed and depended on previous experience, knowledge, and interest.

The results point to the following principles for designing interactive, whole-body exhibits: 1). sensory features to catch visitor attention and provide positive expectations, 2) a coherent combination of the task, game and story to engage and leverage the interaction, and 3) integrated instruction and scientific information to diminish the cognitive load and scaffold the experiential learning.

\section{CONCLUSION}

We examined two questions about whole-body, collaborative exhibit features: 1) which features contributed to engage the visitors in exploration of the exhibition topics and 2) how the exhibit features guided visitors to make sense and transform their experiences into knowledge. Our aim was to increase knowledge about exhibit features and how they support the visitor learning.

The PULSE exhibition was developed to encourage visitors to try out ways of being active. The purpose was to provide the visitors with an opportunity to discover that physical activity is important and fun for everybody and possible to carry out in everyday life. We used the framework of mediational means and mediated actions to understand the visitor experience as dynamic interactions between visitors and exhibit features (mediated means), between group members internally, and between different groups visiting the exhibition (human mediation). The three parameters in experiential learning were used to guide the analysis: reaction, interaction, and sensemaking.

The findings confirmed togetherness, collaboration, and social interaction as a key motivation for the science center visit. However, compared to previous research, the visitors placed extra emphasis on the need for teamwork, strategic coordination, and cooperation due to the use of child's plays and games as mediational means. It was not only the togetherness and collaboration that was important but also the fact that the tasks required strategic consideration and joint coordination to be solved optimally. The playing elements were attractive and motivating due to playfulness and gaming elements, but they also fulfilled their means as tertiary artifacts developing information to the visitors and supporting their sensemaking process.

Regarding individual exhibit features the visitors reacted to the sensory features and were attracted by the scenery, the sounds, cheering visitors, recognizable activities, and child's play stories and games. The physical activities and the gaming elements in the individual exhibits created an atmosphere of joy and engagement supporting visitor interaction. In some exhibits there were contradictions or mismatches between the task, the game, and the story causing misunderstanding and frustration. A close relation between the task and the game supported by scaffolding in form of clear, recognizable stories, and wellconnected, coherent lines of reasoning is essential for visitor interaction. The games had a positive effect on the holding time because the visitors wanted to try out the activity a second time to see whether they could improve their scores and physical techniques.

In general, the exhibition design proved to be very successful at engaging the visitors in physical activity and providing the visitors with the insight that physical activity and collaboration is fun and important. Concerning insight into the biological phenomena, only a few visitors talked about the scientific topics, that is, how to exercise and how to improve their muscle strength, heart rate, and balance in everyday life. Visitor conversation primarily concerned practicalities and the physical effort. However, some sensemaking could be observed when the visitors tacitly during their activities tried to improve 
their movement, either by simply trying out a new physical technique from their own experience or by following instructions from the exhibition labels. In few cases the visitors shared experiences on doing the activities.

The findings are derived from participatory observation and informal talks with the visitors during the walk-alongs and from post-interviews. Both the observation of the visitors' interactions with the exhibits and their emotional response to activities and artifacts provided a good basis for understanding the visitors' engagement and sensemaking. In particular, listening to sound recordings made it possible to document and maintain the researcher's insight into and understanding of the visitors' experiences. However, the high level of activity also affected the researcher's ability to both capture details as well as retain them, which is a challenge with the walk-along method. The postinterviews were valuable to follow up and get further details. At the same time, it is important to emphasize that the visitors are invited for post-reflection and that their answers and stories are not spontaneous reflections, but elicited reflections. In all, these are the methodological limitations of the study. Further, it is important to stress that the findings represent the family or school group as a unit and not specifically the individual children in the unit.

The study supported previous findings that interactive, wholebody exhibits are engaging and enjoyable leading to high visitor interaction (Allen, 2004; Gutwill and Allen, 2010). The study also confirmed findings that interactive, whole-body exhibits are less effective at fostering content-related conversations and reasoning (Dancstep et al., 2015). In return and in contrast to previous studies about holding time the study showed how gaming elements helped to retain visitors who took several trips to improve their scores and hereby work with their physical techniques and collaborative coordination of the task. Wellknown child's plays served as motivating narratives and scripts for the whole-body activities. Redesign should concentrate on improving the scaffolding of verbal intragroup discussions and critical, inventive reflection and sensemaking by integrated,

\section{REFERENCES}

Allen, S. (2004). Designs for Learning: Studying Science Museum Exhibits that Do More Than Entertain. Sci. Ed. 88 (S1), S17-S33. doi:10.1002/sce.20016

Allen, S., and Gutwill, J. (2004). Designing with Multiple Interactives: Five Common Pitfalls. Curator. Mus. J. 47 (2), 199-212. doi:10.1111/j.2151-6952.2004.tb00117.x

Ansbacher, T. (1998). John Dewey's Experience and Education: Lessons for Museums. Curator 41 (1), 36-50. doi:10.1111/j.2151-6952.1998.tb00812.x

Bitgood, S. (1991). Suggested Guidelines for Designing Interactive Exhibits. Visitor Behav. 6 (4), 4-11.

Blud, L. M. (1990). Social Interaction and Learning Among Family Groups Visiting a Museum. Mus. Manag. Curatorship 9, 43-51. doi:10.1080/09647779009515193

Bryman, A. (2016). Social Research Methods. Oxford: Oxford University Press.

Crowley, K., Callanan, M. A., Jipson, J. L., Galco, J., Topping, K., and Shrager, J. (2001). Shared Scientific Thinking in Everyday Parent-Child Activity. Sci. Ed. 85 (6), 712-732. doi:10.1002/sce.1035

Csikszentmihalyi, M., and Hermanson, K. (1995). "Intrinsic Motivation in Museums: Why Does One Want to Learn?," in Public Institutions for Personal Learning: Establishing a Research Agenda. Editors J. H. Falk and L. D. Dierking (Washington D.C.: American Association of Museums), 66-77. dialogue-inviting secondary artifacts, for example, videos, labels, and intuitive, clear-cut lines of reasoning.

\section{DATA AVAILABILITY STATEMENT}

The raw data supporting the conclusions of this article will be made available by the authors, without undue reservation.

\section{ETHICS STATEMENT}

The studies involving human participants were reviewed and approved by Etisk Råd, Det Humanistiske Fakultet, Aalborg Universitet. Written informed consent to participate in this study was provided by the participants' legal guardian/next of kin.

\section{AUTHOR CONTRIBUTIONS}

All authors listed have made a substantial, direct, and intellectual contribution to the work and approved it for publication.

\section{ACKNOWLEDGMENTS}

We would like to thank the Experimentarium (Copenhagen) for its interest and collaboration on this research project, including granting ability to carry out visitor studies in the PULSE exhibition. Special thanks are due to Mette Stentoft, Bent Johan Poulsen, Lene Kofod, and Poul Kattler for providing background knowledge and fruitful discussions. Also, thanks to Louise Bak Søndergaard and Kasper Tikaer Olesen, research assistants at Aalborg University, for their help with data collection.

Dancstep, T., Gutwill, J. P., and Sindorf, L. (2015). Comparing the Visitor Experience at Immersive and Tabletop Exhibits. Curator, Mus. J. 58 (4), 401-422. doi:10.1111/cura.12137

Dewey, J. (2008a). “Art as Experience,” in John Dewey: The Later Works. Editor J. A. Boydson (Carbondale: Southern Illinois University Press), 1-62.

Dewey, J. (2008b). "Experience and Education," in John Dewey: The Later Works. Editor J. A. Boydson (Carbondale: Southern Illinois University Press), 1-62.

Evans, J., and Jones, P. (2011). The Walking Interview: Methodology, Mobility and Place. Appl. Geogr. 31, 849-858. doi:10.1016/j.apgeog.2010.09.005

Experimentarium (2021). 'Pulse Torvet' ('The PULSE Square'). Available at: https:// www.experimentarium.dk/udstillinger/puls-torvet/(Accessed March 1, 2021).

Falk, J. H., and Dierking, L. D. (2013). The Museum Experience Revisited. Walnut Creek: Left Coast Press.

Friedman, A. J. (2010). The Evolution of the Science Museum. Phys. Today 63, 45-51. doi:10.1063/1.3502548

Gilbert, H. (2002). Immersive Exhibitions: What's the Big Deal. Visitor Stud. Today! 5 (3), 10-13.

Gutwill, J. P., and Allen, S. (2010). Facilitating Family Group Inquiry at Science Museum Exhibits. Sci. Ed. 94 (4), 710-742. doi:10.1002/sce.20387

Hooper-Greenhill, E. (2000). Changing Values in the Art Museum: Rethinking Communication and Learning. Int. J. Heritage Stud. 6 (1), 9-31. doi:10.1080/ 135272500363715 
Jakobsson, A., and Davidsson, E. (2012). "Using Sociocultural Frameworks to Understand the Significance of Interactions at Science and Technology Centers and Museums," in Understanding Interactions at Science Centers and Museums: Approaching Sociacultural Perspective. Editors E. Davidsson and A. Jakobsson (Rotterdam: Sense Publisher), 3-21. doi:10.1007/978-94-6091-725-7_2

Jantzen, C. (2013). "Experiencing and Experiences: A Psychological Framework," in Handbook on the Experience Economy. Editors J. Sundbo and F. Sørensen (Cheltenham: Edward Elgar), 146-170.

Jantzen, C., Vetner, M., and Bouchet, J. (2011). Oplevelsesdesign. Tilretteloeggelse Af Unikke Oplevelseskoncepter [Experience Design. Designing Unique Experiential Concepts]. Copenhagen: Samfundslitteratur.

Kahneman, D. (1999). "Objective Happiness," in Well-being: The Foundations of Hedonic Psychology. Editors D. Kahneman, D. E. Diener, and N. Schwarz (New York: Russell Sage Foundation), 1-23.

Kolb, D. A. (1984). Experiential Learning-Experience as the Source of Learning and Development. Englewood Cliffs: Prentice-Hall.

Kusenbach, M. (2003). Street Phenomenology. Ethnography 4 (3), 455-485. doi: $10.1177 / 146613810343007$

Lykke, M., and Skov, M. (2020). Evaluering Af Universitarium - Med Fokus På Udstillingens Unikke Kendertegn. Aalborg: Aalborg Universitet, 76.

Mcclafafferty, T., and Rennie, L. (2012). "Look and Learn: Young Children's Behaviour at an Interactive Exhibit," in Understanding Interactions at Science Centers and Museums: Approaching Sociacultural Perspective. Editors E. Davidsson and A. Jakobsson, 129-145.

McLean, K. (1993). Planning for People in Museum Exhibitions. Washington DC: ASTC. Available at: http://www.astc.org/pubs/mclean.htm (Accessed March 1, 2020).

Murmann, M., and Avraamidou, L. (2014). Animals, Emperors, Senses: Exploring a Story-based Learning Design in a Museum Setting. Int. J. Sci. Educ. B 4 (1), 66-91. doi:10.1080/21548455.2012.760857

Pedretti, E. G. (2002). T. Kuhn Meets T. Rex: Critical Conversations and New Directions in Science Centres and Science Museums'. Sci. Edu. 88 (51), 1-41. doi:10.1080/03057260208560176

Piscitelli, B., and Penfold, L. (2015). Child-centered Practice in Museums: Experiential Learning through Creative Play at the Ipswich Art Gallery. Curator 58 (3), 263-280. doi:10.1111/cura.12113

Sanford, C., Knutson, K., and Crowley, K. (2007). "We Always Spend Time Together on Sundays": How Grandparents and Their Grandchildren Think about and Use Informal Learning Spaces. Visitor Stud. 10 (2), 136-151. doi:10.1080/10645570701585129

Schwartz-Shea, P., and Yanow, D. (2012). Interpretive Research Design. Concepts and Processes. New York: Routledge.
Serrell, B. (2015). Exhibit Labels. An Interpretive Approach. London: Rowman \& Littlefield.

Shaby, N., Assaraf, O. B.-Z., and Tal, T. (2017). The Particular Aspects of Science Museum Exhibits that Encourage Students' Engagement. J. Sci. Educ. Technol. 26 (3), 253-268. doi:10.1007/s10956-016-9676-7

Skov, M., Lykke, M., and Jantzen, C. (2019). Introducing Walk-Alongs in Visitor Studies: A Mobile Method Approach to Studying User Experience. Visitor Stud. 21 (2), 189-210. doi:10.1080/ 10645578.2018.1549396

Skydsgaard, M. A., Møller Andersen, H., and King, H. (2016). Designing Museum Exhibits that Facilitate Visitor Reflection and Discussion. Mus. Manag. Curatorship 31 (1), 48-68. doi:10.1080/09647775.2015.1117237

Temkin, P. D. (2010). Mapping the Customer Journey. Cambridge, MA: Forrester Research.

Wartofsky, M. (1979). Models. Representation and the Scientific Understanding. Netherlands, Dordrecht: Riedel.

Wellington, J. J. (1998). "Interactive Science Centres and Science Education," in Croner's Head of Museums Bulletin (Surrey: Croners Publications Ltd), 16.

Wertsch, J. V. (1998). Mind as Action. New York: Oxford University Press.

Yoon, S. A., Elinich, K., Wang, J., van Schooneveld, J. B., and Anderson, E. (2013). Scaffolding Informal Learning in Science Museums: How Much Is Too Much?. Sci. Ed. 97 (6), 848-877. doi:10.1002/sce.21079

Conflict of Interest: The authors declare that the research was conducted in the absence of any commercial or financial relationships that could be construed as a potential conflict of interest.

Publisher's Note: All claims expressed in this article are solely those of the authors and do not necessarily represent those of their affiliated organizations, or those of the publisher, the editors, and the reviewers. Any product that may be evaluated in this article, or claim that may be made by its manufacturer, is not guaranteed or endorsed by the publisher.

Copyright (c) 2021 Lykke, Skov and Jantzen. This is an open-access article distributed under the terms of the Creative Commons Attribution License (CC BY). The use, distribution or reproduction in other forums is permitted, provided the original author(s) and the copyright owner(s) are credited and that the original publication in this journal is cited, in accordance with accepted academic practice. No use, distribution or reproduction is permitted which does not comply with these terms. 